Diabetologia 10, 459-463 (1974)

(c) by Springer-Verlag 1974

\title{
Effectiveness of the Intestinal Polypeptides, IRP, GIP, VIP and Motilin on Insulin Release in the Rat
}

\author{
D.S. Turner, Lauraine Etheridge, V. Marks, J.C. Brown and V. Mutt \\ Received: February 11, 1974, and in revised form: June 4, 1974
}

Summary. Intestinal insulin releasing polypeptide (IRP) and Gastric inhibitory polypeptide (GIP) have a similar effect on intravenous glucose tolerance in the rat. Both augment the insulin response to intravenous glucose and increase the rate of glucose disappearance. VIP and motilin have no discernible effect. Plasma insulin doseresponse curves to IPP and GIP are similar; both peptides stimulate insulin release in the presence of small blood glucose increments. A direct comparison of the insulin releasing potency of IRP and GIP is not possible as the former is not yet available in pure form.

Key words: Intestinal hormones; insulin release; intestinal insulin releasing polypeptide (IRP); gastric inhibitory peptide (GIP); motilin; vasoactive intestinal polypeptide (VIP); glucagon.
A fraction from porcine duodenojejunal mucosa, intestinal insulin releasing polypeptide (IRP), has been prepared [1] and the suggestion made that it is responsible for the greater plasma insulin response to oral as compared to intravenous glucose. The possibility that the effects observed could be due to contamination of IRP by secretin, pancreozymin/cholecystokinin (CCK) or intestinal glucagon-like immunoreactivity (GLI) has been investigated and considered unlikely [2] on the evidence available. Three additiona! intestinal polypeptides, vasoactive intestinal polypeptide (VIP) [3], gastric inhibitory polypeptide (GIP) [4] and motilin [5] have recently been purified. All appear to be hormonally active and GIP has been shown to stimulate insulin release [6]. It was considered necessary, therefore, to investigate each of them to assess their ability to explain the observed effects of IRP on insulin secretion and their possible involvement in the intestinal regulation of insulin release.

Studies similar to those previously reported with $\operatorname{IRP}[1,2]$ were performed using pure or partially pure preparations of GIP, VIP and motilin. In addition further studies were made of the conditions affecting IRP and GIP mediated insulin release in rats in vivo.

\section{Materials and Methods}

Intestinal insulin releasing polypeptide (IRP) was prepared by the method of Turner etal. [2]. A partially pure GIP preparation, containing approximately $40 \%$ GIP, and pure GIP were prepared by the method of Brown et al. [4]. Vasoactive intestinal polypeptide was prepared according to Said and Mutt [3] and motilin by the method of Brown et al. [5]. Insulin-free pork glucagon was given by Dr. Mary Root, Lilly Research Laboratories, Indianapolis, U.S.A. All solutions for injection contained gelatin, $0.05 \%$, as a carrier protein.
Overnight fasted twelve week old male Wistar rats weighing between 260 and $280 \mathrm{~g}$ were used for all experiments. Rats were anaesthetised by the intraperitoneal injection of sodium pentobarbitone, $40 \mathrm{mg} / \mathrm{kg}$. Intravenous injections and blood sampling were carried out as previously described [2]. Blood glucose was measured by a glucose oxidase procedure [7] and plasma insulin by a double antibody radioimmunoassay [8], using human insulin as standard.

Radioimmunoassay for GIP was performed on the IRP preparation used here by J.C.B. and by Dr. S.R. Bloom of the Middlesex Hospital, Iondon. J.C.B. found an apparent GIP content of $1.2 \%$, but the dilution slope of the cross reactivity was markedly different from that of GIP standards and other samples having excellent insulin releasing activity showed no detectable GIP content. Dr. S. R. Bloom found a content of $400 \mathrm{ng} / \mathrm{mg}$. It is thus difficult to be certain of the nature or quantity of GIP immunoreactivity present in the IRP preparation.

\section{Results}

\section{The Effect of Partially Pure GIP on Intravenous} Glucose Tolerance in the Rat

The effect of partially pure GIP, injected intravenously at a dose of $5 \mu \mathrm{g} / \mathrm{kg}$, on the blood glucose and plasma insulin response to intravenous glucose is shown in Fig. 1. The glucose disappearance rate in rats that received glucose plus GIP was faster than that in the rats receiving glucose alone and their mean blood glucose levels were significantly lower at $30 \mathrm{~min}(p<$ 0.02 ) and $60 \mathrm{~min}(p<0.05)$ after glucose injection. Mean plasma insulin levels in rats given GIP in addition to glucose were significantly higher at $5 \mathrm{~min}(p<$ $0.01)$ and $10 \mathrm{~min}(p<0.05)$ than in animals given glucose alone. 


\section{Dose Response to Pure GIP}

The curve obtained by plotting "glucose dependent" insulin releasing activity - expressed as a percentage of control values - against the dose of GIP is shown in Fig. 2. Plasma insulin levels are given in Table 1 . The data represent mean plasma insulin levels observed in groups of eight rats, five minutes after the intravenous injection of glucose plus GIP, and in the figure are expressed as a percentage of the $5 \mathrm{~min}$ insulin level in control animals receiving glucose alone.

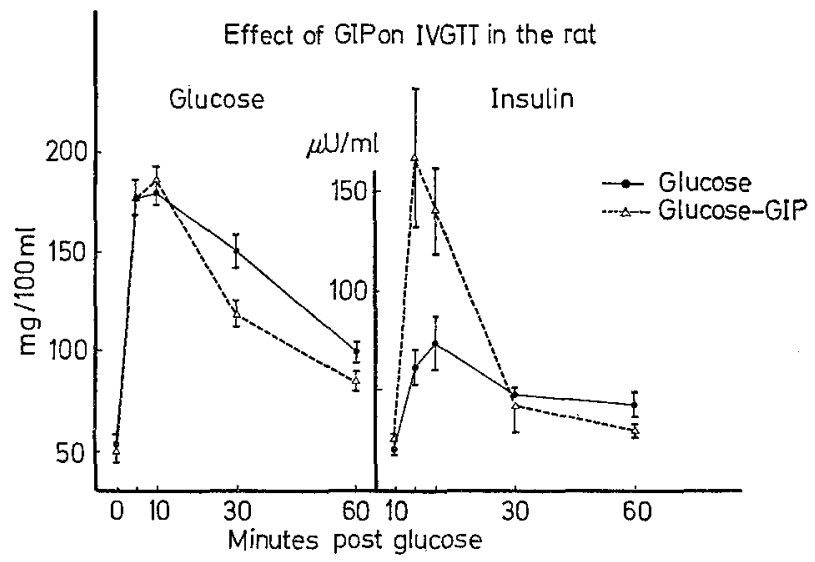

Fig. 1. The effect of GIP on intravenous glucose tolerance in the rat. Mean \pm S.E.M. of blood glucose and plasma insulin levels in groups of 8 rats after the intravenous injection of $5.0 \mu \mathrm{g} / \mathrm{kg} 40 \%$ GIP in glucose $(0.625 \mathrm{~g} / \mathrm{kg})$ over $11 / 2 \mathrm{~min}$. Control animals received glucose alone, 0.625 $\mathrm{g} / \mathrm{kg}$. - - glucose alone, - - - - plus GIP

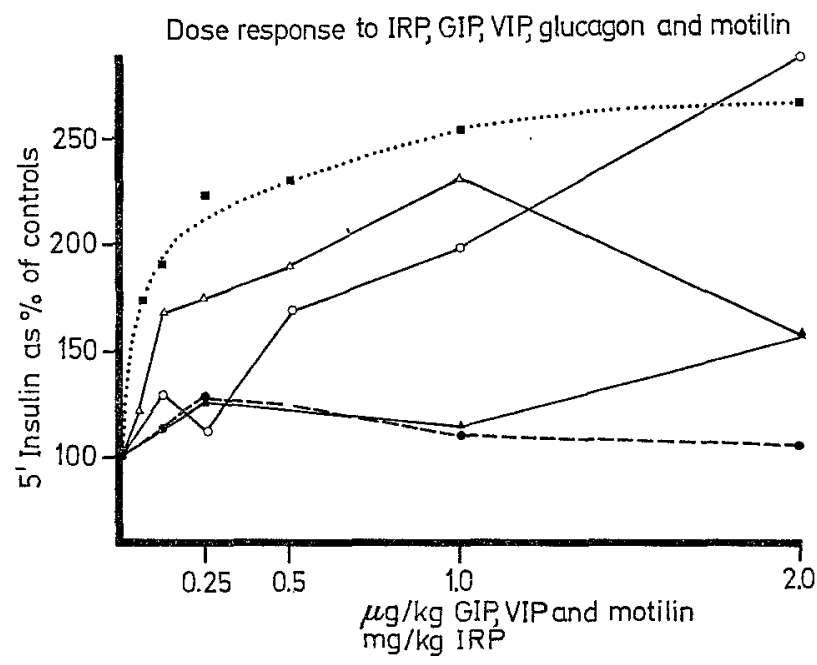

Fig. 2. The dose response to IRP, GIP, VIP, glucagon and motilin. Mean 5 min plasma insulin levels expressed as a percentage of those in animals which received $0.625 \mathrm{~g} / \mathrm{kg}$ glucose i.v. alone over $1 \frac{1 / 2}{2} \mathrm{~min}$. The doses of peptide indicated were dissolved in the i.v. glucose injection. …..... IRP, $\frac{\text { IRP }}{- \text { Motilin, - GIP, }} \mathrm{O}$ Glucagon
Significant augmentation of insulin release $(p<$ $0.01)$ was produced by $0.125 \mu \mathrm{g} / \mathrm{kg}$ GIP. A dose of $1.0 \mu \mathrm{g} / \mathrm{kg}$ GIP had a maximal insulin releasing effect. At a higher dose, $2.0 \mu \mathrm{g} / \mathrm{kg}$ there was a suggestion of a reduction in effect. A plot of the mean 5 min plasma insulin levels against log GIP dose is shown in Fig. 3 and demonstrates a log-linear relationship over much of the observed range.

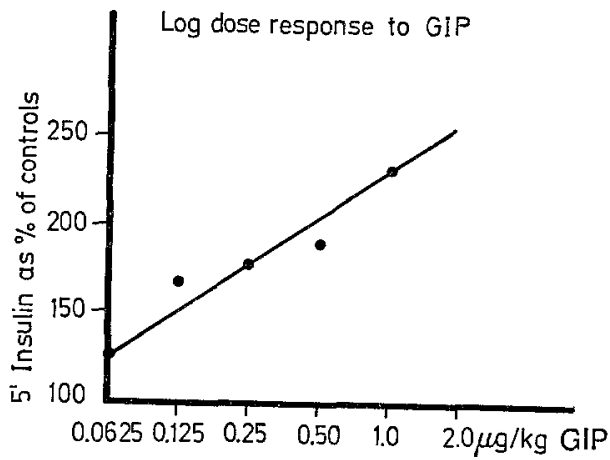

Fig. 3. Log dose response to GIP. Mean 5 min plasma insulin levels as a percentage of values for glucose alone, plotted against log dose of GIP

Data obtained with IRP and glucagon are included for comparison. Crude IRP at a dose of $62.5 \mu \mathrm{g} / \mathrm{kg}$ was sufficient to stimulate significantly insulin release, while $0.5 \mu \mathrm{g} / \mathrm{kg}$ glucagon was required to produce a significant stimulation.

\section{The Effect of Motilin and VIP on Insulin Release}

The lack of effect upon glucose mediated insulin release of either VIP or motilin at various dose levels is shown in Fig. 2 and Table 1. In consequence no further studies were made of these two peptides.

\section{The Effect of Glucose Dosage on the Insulinaemic Response to IRP}

a) A constant dose of IRP $(0.5 \mathrm{mg} / \mathrm{kg})$ was administered intravenously, simultaneously with differing quantities of glucose. Blood glucose and plasma insulin levels were measured 5 min after the injection. The results are shown in Fig. 4. The injection of IRP plus glucose, $78 \mathrm{mg} / \mathrm{kg}$, resulted in a $13 \mathrm{mg} / 100 \mathrm{ml}$ increment in the mean $5 . \min$ blood glucose level and was associated with a significant increase in plasma insulin level compared to animals given IRP in saline. The mean rise in plasma insulin was equal to that ordinarily associated with a rise in blood glucose of about $150 \mathrm{mg} /$ $100 \mathrm{ml}$ produced by intravenous glucose alone. With increasing amounts of glucose added to the IRP a dose response curve for insulin release against blood glucose concentration was observed. This moved towards a plateau at blood glucose levels above $200 \mathrm{mg} / 100 \mathrm{ml}$.

b) On this occasion the response to different amounts of intravenous glucose in the presence or absence of IRP was investigated. The results are 
shown in Fig. 5. Five minute plasma insulin levels were significantly higher at all glucose dose levels in animals give IRP plus glucose than in those given glucose alone. IRP was not associated with any significant difference in 5 min blood glucose levels at any glucose dose except the lowest. glucose alone. There were no differences in $5 \mathrm{~min}$ blood glucose levels between the two groups.

b) Because of differences between IRP and GIP treated animals in the $5 \mathrm{~min}$ blood glucose response to the lowest doses of glucose in experiments $4 \mathrm{~b}$ and $5 \mathrm{a}$, further experiments were carried out to test the re-

Table 1. Mean \pm S.E.M. 5 min plasma insulin levels in rats receiving the dose of peptide indicated together with glucose $0.625 \mathrm{~g} / \mathrm{kg}$, administered $i . v$. over $11 / 2 \mathrm{~min}$

\begin{tabular}{|c|c|c|c|c|c|c|c|c|}
\hline \multirow{2}{*}{ Polypeptide } & \multirow{2}{*}{$\begin{array}{l}\text { No. of } \\
\text { animals } \\
\text { per group }\end{array}$} & \multicolumn{7}{|c|}{ Dose of Polypeptide } \\
\hline & & Zero & $0.0625 \mu \mathrm{g} / \mathrm{kg}^{\mathrm{a}}$ & $0.125 \mu \mathrm{g} / \mathrm{kg}^{\mathrm{a}}$ & $0.25 \mu \mathrm{g} / \mathrm{kg}^{\mathrm{a}}$ & $0.50 \mu \mathrm{g} / \mathrm{kg}^{\mathrm{a}}$ & $1.0 \mu \mathrm{g} / \mathrm{kg}^{\mathrm{a}}$ & $2.0 \mu \mathrm{g} / \mathrm{kg}^{2}$ \\
\hline $\begin{array}{l}\text { IRP } \\
p \text { for } \\
\text { difference } \\
\text { from control }\end{array}$ & 8 & $145 \pm 13.06$ & $\begin{array}{l}253 \pm 27.39 \\
<0.005\end{array}$ & $\begin{array}{l}272 \pm 18.51 \\
<0.001\end{array}$ & $\begin{array}{l}326 \pm 20.21 \\
<0.001\end{array}$ & $\begin{array}{l}334 \pm 24.37 \\
<0.001\end{array}$ & $\begin{array}{l}371 \pm 25.02 \\
<0.001\end{array}$ & $\begin{array}{l}390 \pm 14.40 \\
<0.001\end{array}$ \\
\hline $\begin{array}{l}\text { GIP } \\
p\end{array}$ & 8 & $101 \pm 4.35$ & $\begin{array}{l}126 \pm 17.85 \\
>0.20\end{array}$ & $\begin{array}{l}170 \pm 20.20 \\
<0.01\end{array}$ & $\begin{array}{l}177 \pm 16.93 \\
<0.005\end{array}$ & $\begin{array}{l}192 \pm 24.37 \\
<0.01\end{array}$ & $\begin{array}{l}235 \pm 25.93 \\
<0.001\end{array}$ & $\begin{array}{l}161 \pm 27.21 \\
>0.05\end{array}$ \\
\hline $\begin{array}{l}\text { Motilin } \\
p\end{array}$ & 8 & $92 \pm 5.95$ & - & $\begin{array}{l}103 \pm 13.76 \\
>0.50\end{array}$ & $\begin{array}{l}117 \pm 11.35 \\
>0.05\end{array}$ & $\begin{array}{l}114 \pm 10.39 \\
>0.05\end{array}$ & $\begin{array}{l}101 \pm 16.17 \\
>0.60\end{array}$ & $\begin{array}{c}96 \pm 6.92 \\
>0.70\end{array}$ \\
\hline $\begin{array}{l}\text { VIP } \\
p\end{array}$ & 6 & $142 \pm 34.80$ & - & - & $\begin{array}{l}179 \pm 17.58 \\
>0.50\end{array}$ & - & $\begin{array}{l}162+25.93 \\
>0.70\end{array}$ & $\begin{array}{l}223 \pm 31.03 \\
>0.10\end{array}$ \\
\hline $\begin{array}{l}\text { Glucagon } \\
p\end{array}$ & 8 & $208 \pm 15.94$ & - & $\begin{array}{l}268 \pm 24.06 \\
>0.05\end{array}$ & $\begin{array}{l}230 \pm 30.22 \\
>0.90\end{array}$ & $\begin{array}{l}352 \pm 34.63 \\
<0.005\end{array}$ & $\begin{array}{l}400 \pm 29.42 \\
<0.001\end{array}$ & $\begin{array}{l}602 \pm 45.87 \\
<0.001\end{array}$ \\
\hline
\end{tabular}

a For IRP read mg/kg

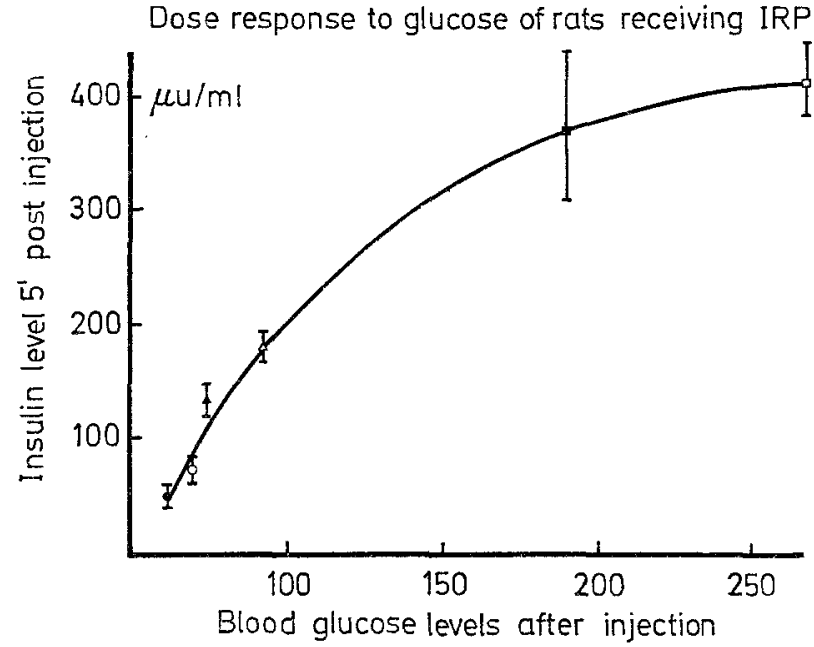

Fig. 4. Dose response to glucose of rats receiving IRP, $0.5 \mathrm{mg} / \mathrm{kg}$. Mean \pm S.E.M. $5 \mathrm{~min}$ plasma insulin levels following i.v. injection of glucose plus IRP over $1 \frac{1}{2} \mathrm{~min}$, plotted against mean blood glucose levels at $5 \mathrm{~min}$ in groups of eight rats receiving glucose doses: zero, O $78 \mathrm{mg} / \mathrm{kg}, \Delta 156 \mathrm{mg} / \mathrm{kg}, \Delta 312 \mathrm{mg} / \mathrm{kg}, \mathrm{L} \quad 625 \mathrm{mg} / \mathrm{kg}$, $\square 1230 \mathrm{mg} / \mathrm{kg}$

\section{Glucose Dose and the Insulinaemic Response to GIP}

a) The results of experiments similar to $4 \mathrm{~b}$, but in which pure GIP, $0.5 \mu \mathrm{g} / \mathrm{kg}$ was substituted for IRP, are shown in Fig. 6. The 5 min plasma insulin levels were significantly higher, at all glucose dosages, in animals receiving GIP plus glucose than in those given

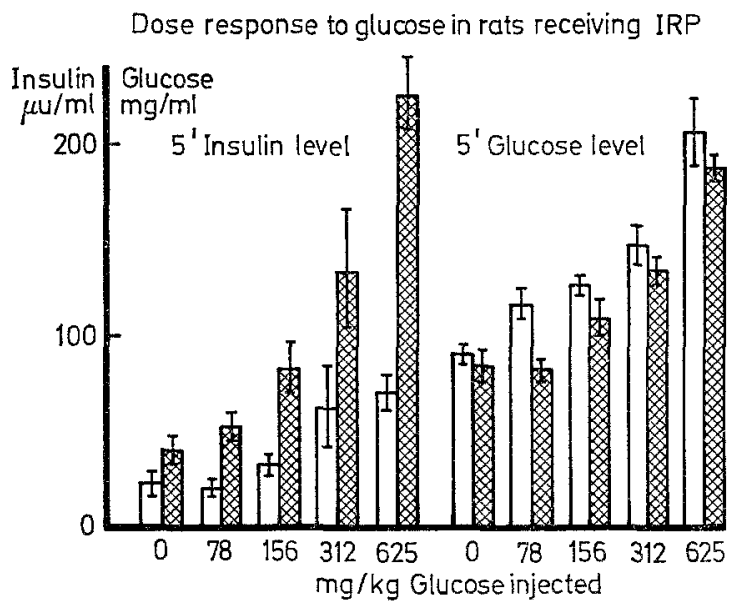

Fig. 5. Dose response of rats to glucose, and to glucose plus $0.5 \mathrm{mg} / \mathrm{kg}$ IRP. Mean \pm S.E.M. of $5 \mathrm{~min}$ plasma insulin levels in groups of eight rats and mean \pm S.E.M. $5 \mathrm{~min}$ blood glucose levels following intravenous injection. over $1 \frac{1}{2}$ min. Clear columns show results with glucose alone and hatched columns those with glucose plus IRP

producibility of the apparent reduction of blood glucose levels in IRP treated animals given small doses of glucose, compared with animals given glucose without IRP. In these experiments control animals were given glucose (78 mg/kg body weight) and experimental animals received a similar amount of glucose plus either IRP $(0.5 \mathrm{mg} / \mathrm{kg})$ or GIP $(0.5 \mu \mathrm{g} / \mathrm{kg})$. The results are shown in Fig. 7. There was no difference in the 
5 min blood glucose level between any of the three groups and IRP and GIP evoked similarly augmented 5 min plasma insulin responses.

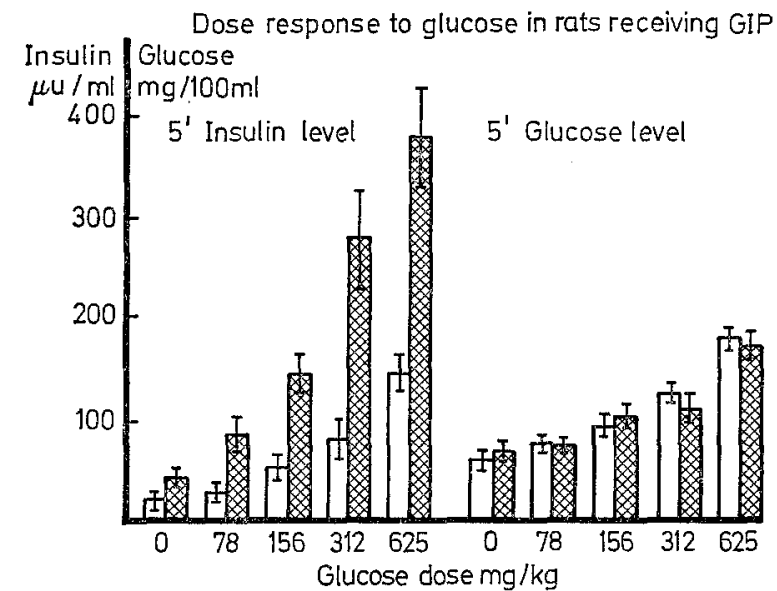

Fig. 6. Dose response of rats to glucose, and to glucose plus $0.5 \mu \mathrm{g} / \mathrm{kg}$ GIP. Mean \pm S.E.M. of $5 \mathrm{~min}$ plasma. insulin levels in groups of eight rats and mean \pm S.E.M. $5 \mathrm{~min}$ blood glucose levels following intravenous injection over $1 \frac{1}{2}$ min. Clear columns show results with glucose alone and hatched columns those with glucose plus IRP

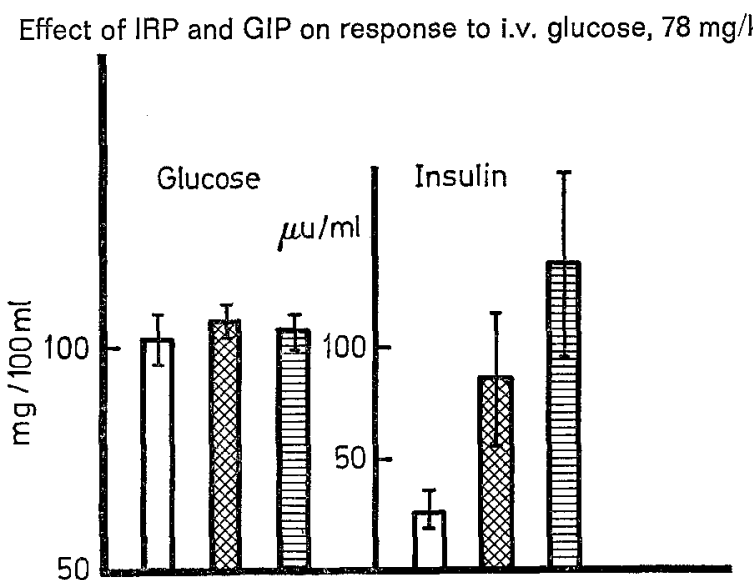

Fig. 7. The effect of IRP and GIP on the response to intravenous glucose, $78 \mathrm{mg} / \mathrm{kg}$. Mean \pm S.F.M. $5 \mathrm{~min}$ plasma insulin and blood glucose levels in groups of eight rats following i.v. injection over $1 \frac{1}{2} \mathrm{~min}$

\section{Discussion}

The effect of partially purified GIP on the plasma insulin response to intravenous glucose, in the rat, resembled that previously described for IRP [2]. Moreover, the shape of the dose response curve to the two preparations was similar; both substances produced a log-linear dose-response curve. Both IRP and GIP augmented insulin release with blood glucose increments which were too small to produce significant rises in plasma insulin levels when produced by intravenons glucose alone. This is reminiscent of the sit- uation often observed during oral glucose tolerance tests in which a large rise in plasma insulin is associated with small increments in blood glucose concentration. Both GIP and IRP would seem to qualify, therefore, for consideration as the intestinal mediator of the augmented insulinaemic response to enteric glucose administration.

It is clear that neither VIP nor motilin need be considered further, since, unlike IRP and GIP, neither polypeptide had a significant effect on glucose stimulated insulin release. A direct comparison of the insulin releasing potency of IRP and GIP was not possible due to the known, but unquantified, impurity of the IRP preparation currently available. The comparative data for glucagon used under the same conditions suggests that on a weight for weight basis GIP has an insulin releasing potency approximately four times that of glucagon, or in molar terms there is an approximately six fold difference in potency.

Our experiments revealed no essential difference between the insulin releasing effect of IRP and GIP. The question arises, therefore, as to whether the active component of the IRP preparation is GIP or an as yet uncharacterised polypeptide, and secondly whether GIP is normally involved in the insulin secretory response to oral glucose in man. A pointer to the possible non-identity of IRP and GIP comes from the observation that extracts of duodenum, a source of GIP, do not exhibit significant insulin releasing activity when prepared by methods used to produce IRP from the jejunum $[9,10]$. The final answers to both questions must await further experiments, and ultimately the purification and chemical characterisation of the active component of IRP.

It is likely that GIP is closely related to, but not necessarily identical with, IRP, and that, as with other gastrointestinal polypeptides there is some sharing or overlapping of structure and biological activities.

Acknowledgements. The authors wish to thank the British Diabetic Association and the Wellcome Foundation Limited for their generous financial assistance.

\section{References}

1. Turner, D.S., Marks, V.: Enhancement of glucosestimulated insulin release by an intestinal polypeptide in rats. Lancet $1972 \mathrm{I}, 1095-1097$

2. Turner, D.S., Shabaan, A., Etheridge, Lauraine, Marks, V.: The effect of an intestinal polypeptide fraction on insulin release in the rat in vitro and in vivo. Endocrinology 93, 1325-1328 (1973)

3. Said, S.I., Mutt, V.: Isolation from porcine-intestinal wall of a vasoactive octacosapeptide related to secretin and to glucagon. Europ. J. Biochem. 28, 199-204 (1972)

4. Brown, J.C., Mutt, V., Pederson, R.A.: Further purification of a polypeptide demonstrating enterogastrone activity. J. Physiol. (Lond.) 209, 57-64 (1970)

5. Brown, J.C., Cook, M.A., Dryburgh, J.R.: Motilin, a gastric motor activity-stimulating polypeptide; final 
purification, amino acid composition, and c-terminal residues. Gastroenterology 62, 401-404 (1973)

6. Dupré, J., Ross, S.A., Watson, D., Brown, J.C.: Stimulation of insulin secretion by Gastric Inhibitory Polypeptide in man. J. clin. Endocr. 37, 826-828 (1973)

7. Huggett, A.St.G., Nixon, D.: Use of glucose oxidase, peroxidase, and o-dianisidine in determination of blood and urinary glucose. Lancet 1957 II, 368-370

8. Samols, E., Bilkus, D.A.: A comparison of insulin radioimmunoassays. Proc. Soc. exp. Biol. (N.Y.) 115, $79-84(1964)$
9. Moody, A.J., Markussen, J., Schaich-Fries, A., Sundby, F., Malaisse, W.J., Malaisse-Lagae, F. : The insulin releasing activities of extracts of pork intestine. Diabetologia 6, 135-140 (1970)

10. Turner, D.S.: Unpublished observations

Dr. D.S. Turner

Dept. of Biochemistry

Univ. of Surrey

Guildford, Surrey GU2 5XH

England 